\title{
Thermo-Structural Analysis of First Stage Gas Turbine Rotor Blade Materials for Optimum Service Performance
}

\author{
Aniekan Ikpe E. ${ }^{a^{*}}$, Oghenefejiro Efe-Ononeme E. ${ }^{b}$, Godfrey Ariavie $O .^{c}$ \\ $a^{a^{*}, b, c}$ Institution Department of Mechanical Engineering, Faculty of Engineering, University of Benin, P.M.B. \\ 1154, Nigeria

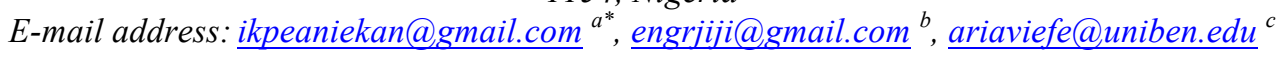

ORCID numbers of authors:

0000-0001-9069-9676 ${ }^{a}, 0000-0003-0893-0600^{b}, 0000-0002-9614-5962^{c}$

Received date: 25.07 .2018

Accepted date: 10.08 .2018

\begin{abstract}
During gas turbine operation, the vibration that occurs at high speed, hot gases entering the combustion chamber and other operational factors affect the longevity of gas turbine blade. This paper is focused on the selection of suitable materials that can withstand the severe working condition and thermo-structural analysis using Finite Element method (FEM) to determine the behaviour of each material under service condition. Cambridge Engineering Software (CES) was employed in the material selection process where GTD111, U500 and IN 738 were identified prior to analyzing U500 and IN 738 due to desired mechanical properties over GTD111. Employing ANSYS R15.0 in the steady state thermal analysis, maximum service temperature of $736.49^{\circ} \mathrm{C}$ and maximum Total heat flux of $4.345 \times 10^{5} \mathrm{~W} / \mathrm{m}^{2}$ was obtained for IN 738 material while maximum service temperature of $728.29^{\circ} \mathrm{C}$ and maximum Total heat flux of $4.1746 \times 10^{5} \mathrm{~W} / \mathrm{m}^{2}$ was obtained for U500 blade material. For structural static analysis, maximum von-mises stress of $454 \mathrm{MPa}$ and total deformation of 0.16221 obtained for IN 738 while maximum von-mises stress of $416 \mathrm{MPa}$ and total deformation of 0.12125 was obtained for U500 blade material. While the FEA analytical results for both materials exhibited less variations between each other, IN 738 displayed better thermal characteristics, whereas, U500 presented satisfactory structural static results and above all, von-mises stresses obtained for both materials was below their yield strength and melting temperature. Hence, gas turbine blade materials should be assessed thoroughly for structural and thermal conditions before manufacturing.
\end{abstract}

Keywords: Gas turbine, Turbine blade, Temperature, Material properties, Stress, Deformation.

\section{Introduction}

The gas turbine engines are more critical to the operation of power plants, aircraft and heavy duty vehicles. A typical gas turbine engine consists of three major parts namely; compressor, combustion chamber and the turbine in addition to the generator [1]. Gas turbine blades are the specific component responsible for extracting energy from the high temperature and high pressure gas produced from the combustion chamber. The combustible gas in the process converts potential energy of the stationary blade to kinetic energy of the blade which in turn generates electrical power. During the operation of gas turbine engine, the turbine blades are subjected to high temperatures and stresses [2]. Turbine blades are exposed to loads that can cause failure during operation, therefore, the gas turbine blade component must be design with 
in-depth consideration of vibration and thermal stresses induced on the blade in service condition [3]. A major cause of turbine blade failure is High Cycle Fatigue (HCF) caused by repeated cyclic loads on the rotor blade [4]. Gas temperatures at the turbine inlet is between $1200^{\circ} \mathrm{C}$ to $1600^{\circ} \mathrm{C}$, but some as a result of over loading have increased inlet temperatures as high as $1600^{\circ} \mathrm{C}$ which may cause fatigue and fracture of the blades/discs [5]. Boyce [6] reported that the 5th stage of the low pressure turbine operates at a temperature of about $800^{\circ} \mathrm{C}$, while the 1st stage intermediate pressure turbine operates at a temperature of about $1100^{\circ} \mathrm{C}$ and the 1st stage high pressure turbine operates at a temperature of about $1500^{\circ} \mathrm{C}$ respectively. According to Ikpe et al. [7], the high pressure turbine is exposed to the most intensed temperature $\left(450^{\circ}-1300^{\circ}\right)$ and pressure while the Low Pressure (LP) turbine is exposed to lower temperature $\left(80^{\circ}-400^{\circ}\right)$ air pressure. Hot gases from the combustor are accelerated prior to entering the gas turbine and this significantly lowers the turbine maximum temperature from approximately $1800^{\circ} \mathrm{C}$ to approximately about $1100^{\circ} \mathrm{C}$ while entering the first turbine stage [8]. These challenges can be unravelled through the use of materials with relatively high melting point (such as material with temperature above the operating condition of the gas turbine engine), surface coating and cooling techniques which are the areas that will be addressed in this paper. Choi and Lee [19] studied a gas turbine failure scenario by investigating the broken surface of the blade and stress analysis of the blade and was observed that the maximum stress occurred due to the pressure profiles developed during operation. Umamaheswararao and Mallikarjunarao [10] conducted a structural static analysis on three potential gas turbine blade materials which included mild steel, N-155 and Inconel 718. It was found that displacement is less for INCONEL 718 compared to mild steel and N- 155, while the von-misses stress was within the yield strength of the material with optimum deformation compared to mild steel and N-155. Kumar and Pandey [11] investigated the potentials of super alloy X, Nimonic 80A and Inconel 625 as possible turbine blade materials at three different speeds viz; 20000, 40000 and 60000 RPM and found out that the bent profile of Inconel 625 is the best combination for all the speeds. Sushila et al. [12] carried out failure analysis on first stage IN738 gas turbine blade tip cracking to determine the causes of gas turbine blade failure of $30 \mathrm{MW}$ thermal power plant. It was found that surface degradation due to overheating, oxidation, fatigue, degradation of coatings, hot corrosion, sulphidation, embrittlement and thermal aging are the major causes. Difference in operating condition of the HP and LP turbine has over the years resulted in the design of HP and LP turbine blades which are greatly different in material and cooling options despite the same thermodynamic and aerodynamic principles In this study, thermal-structural FEA was carried out on potential turbine blade materials to check their suitability.

\section{Materials and Method}

The Initial search was performed using fatigue strength and density as the basis in Cambridge Engineering Software (CES) Edupack to determine the materials with maximum fatigue strength and minimum density under service temperature between $800^{\circ} \mathrm{C}$ and $1300^{\circ} \mathrm{C}$ without failure, and possible materials were captured as presented in Fig. 1. 


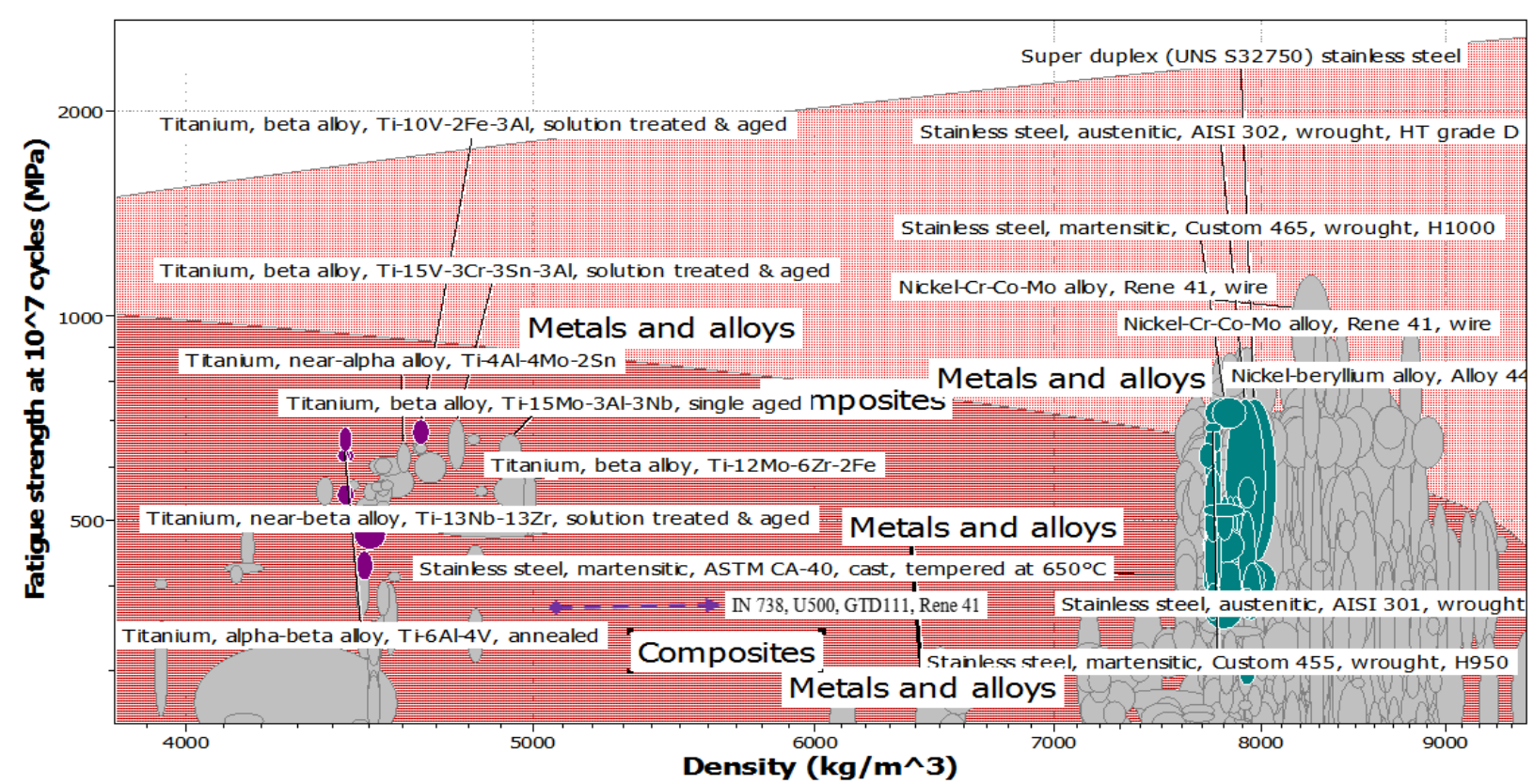

Fig. 1. Graph of Fatigue Strength against Density

Further search was performed using maximum yield strength and density as the basis in CES Edupack to determine the materials with reference service temperature (between $500^{\circ} \mathrm{C}$ and $950^{\circ} \mathrm{C}$ ) according to existing literatures [13]. The box method was applied for optimization and selection of possible materials suitable for gas turbine blade as shown in Fig. 2.

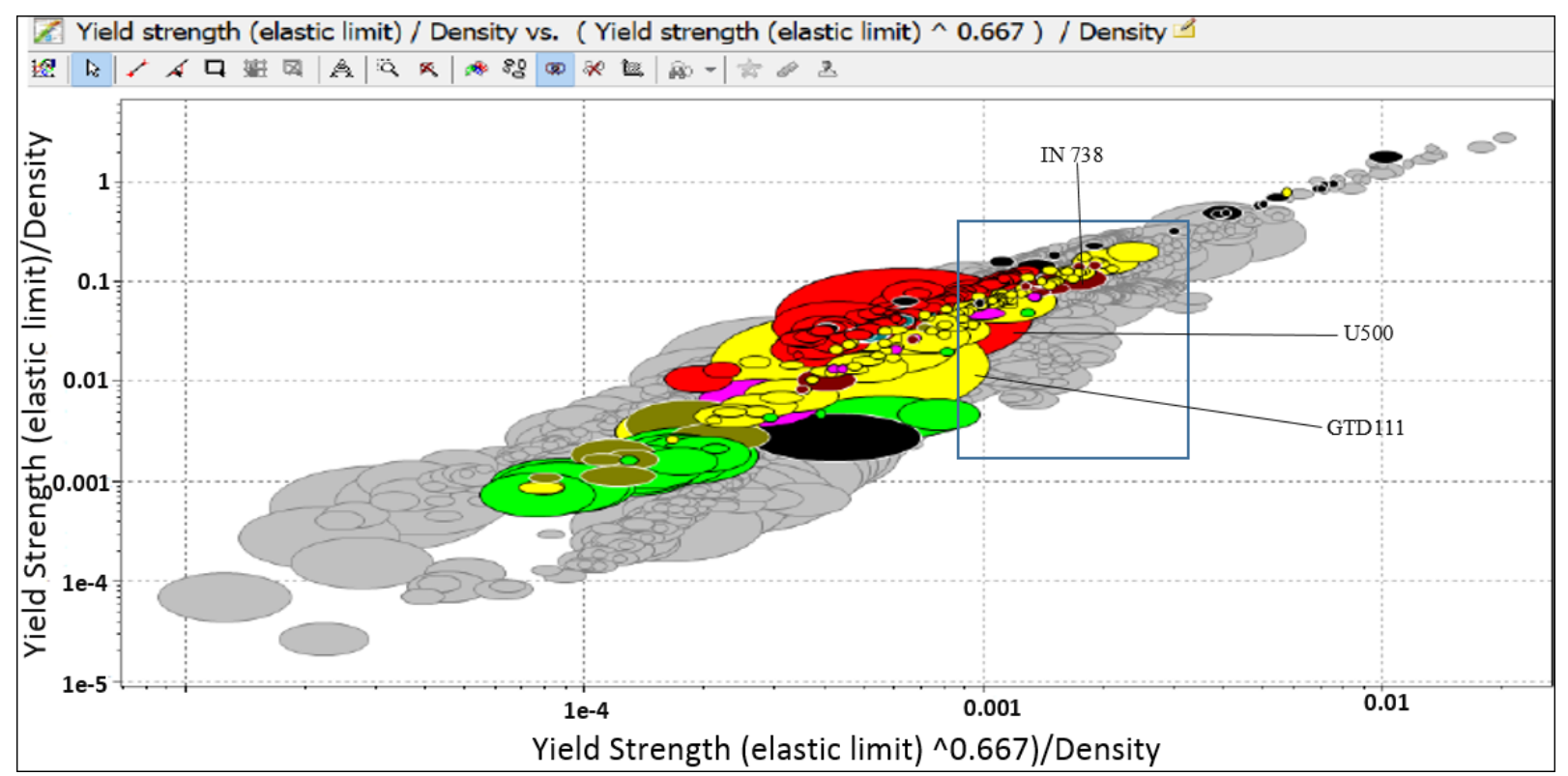

Fig. 2. Graph of Yield Strength against Density

As shown in Fig. 2, the three materials (GTD111, U500 and IN 738) were indicated in the second search which were also captured in the initial search indicated with broken arrow as shown in Fig. 1. These three super alloy materials are in agreement with studies on gas turbine blade materials by Nageswara [14]. These blade material properties were created with ANSYS by double clicking on the engineering material data located in ANSYS workbench. A new page having engineering materials data opened right next to project. The default material on ANSYS was structural steel. A list of several possible properties found on ANSYS was found in the Toolbox. After selecting the appropriate properties for the material intended to be created, the 
material properties then displayed. Properties of the three possible gas turbine blade materials selected in Fig. 2 are summarized in Table 1. Nominal composition of the various blade material are provided in the Table 2.

Table 1. Material Properties of possible Gas Turbine Blade

\begin{tabular}{lccc}
\hline Materials & GTD 111 & $\mathrm{U} 500$ & IN 738 \\
\hline Specific Heat (J/KgK) & 460 & 500 & 510 \\
Young's Modulus (GPa) & 130 & $190-210$ & 149 \\
Density (kg/m3) & 8870 & 8027 & 8550 \\
Poison's ratio & 0.33 & $0.27-0.30$ & 0.30 \\
Thermal conductivity (W/mk) & 16 & 16.2 & 14.3 \\
Thermal expansion (0C) & $9 \times 10^{-6}$ & $17.5 \times 10^{-6}$ & $12.5 \times 10^{-6}$ \\
Yield strength (MPa) & 564.32 & 500 & 792 \\
Melting temperature (0C) & 1699 & 1360 & 1400 \\
Bulk Modulus (Pa) & $1.0833 \times 10^{\wedge} 11$ & $1.583 \times 10^{\wedge} 11$ & $1.247 \times 10^{\wedge} 10$ \\
Shear Modulus (Pa) & $5 \times 10^{\wedge}$ & $7.307 \times 10^{\wedge} 10$ & $5.730 \times 10^{\wedge 10}$ \\
\hline
\end{tabular}

Table 2. Nominal Composition of Possible Gas Turbine Blade Material

\begin{tabular}{lllllllllllll}
\hline Materials & \multicolumn{11}{c}{ Composition (Alloying Elements) } \\
\cline { 2 - 13 } & $\mathrm{Ni}$ & $\mathrm{Cr}$ & $\mathrm{Co}$ & $\mathrm{Ti}$ & $\mathrm{Al}$ & $\mathrm{C}$ & $\mathrm{W}$ & Mo & $\mathrm{B}$ & $\mathrm{Nb}$ & $\mathrm{Ta}$ & $\mathrm{Fe}$ \\
IN 738 & $\mathrm{Bal}$ & 16 & 8.3 & 3.4 & 3.4 & 0.10 & 2.6 & 1.75 & 0.001 & 0.9 & 1.75 & 0.2 \\
GTD111 & $\mathrm{Bal}$ & 14 & 9.5 & 4.9 & 3 & 0.10 & 3.8 & 4.5 & 0.01 & - & 2.8 & - \\
U500 & $\mathrm{Bal}$ & 17.5 & 16.5 & 3.9 & 2.9 & - & 0.8 & 4 & 0.01 & - & & 4 \\
\hline
\end{tabular}

\subsection{FEA of Gas Turbine Blade}

The FEA configured the turbine blade model for analysis using a complex system of points or nodes connected into a grid known as mesh. The nodes were arranged at a specific density throughout the model. The geometry of the gas turbine blade is modeled in SOLIDWORKS and then imported into ANSYS for meshing. The aero foil profile of the rotor blade was generated on the XZ plane with the help of key points defined by the coordinates. Then a number of splines were fitted through the key points, creating the $2 \mathrm{D}$ aero foil shape. The geometry of the blade was meshed with 8 nodded tetrahedral brick element but the element type used for this purpose was Tetrahedron 10. It has 3 degrees of freedom per node, that is, translation in $\mathrm{X}, \mathrm{Y}$ and $\mathrm{Z}$ directions were used. The element has plasticity, creep, swelling, stress stiffening, large deflection, and large strain capabilities etc. The blade dimensions are given in Table 3, while Fig. 3 represents the gas turbine blade geometrical models created in SOLIDWORKS and meshed gas Turbine blade using ANSYS. The steps employed in the course of the analysis are as follows;

i. Creating a three dimensional model in SOLIDWORKS software 2016

ii. Import the SOLIDWORKS model in ANSYS 15.0 software

iii. Mesh the imported model in ANSYS

iv. Apply boundary conditions and,

v. Solve the system equations to find out the unknowns

vi. Validation of solutions obtained with the operating conditions 
Table 3. Gas Turbine Blade Dimensions

\begin{tabular}{ll}
\hline Parameter & Value \\
\hline Name & NACA6409 9\% \\
Blade Span (mm) & $120 \mathrm{~mm}$ \\
Blade Axial Chord Length (mm) & $68.30 \mathrm{~mm}$ \\
Blade Root Length (mm) & $60 \mathrm{~mm}$ \\
Thickness (\%) & 100 \\
Pitch (deg) & 14 \\
\hline
\end{tabular}

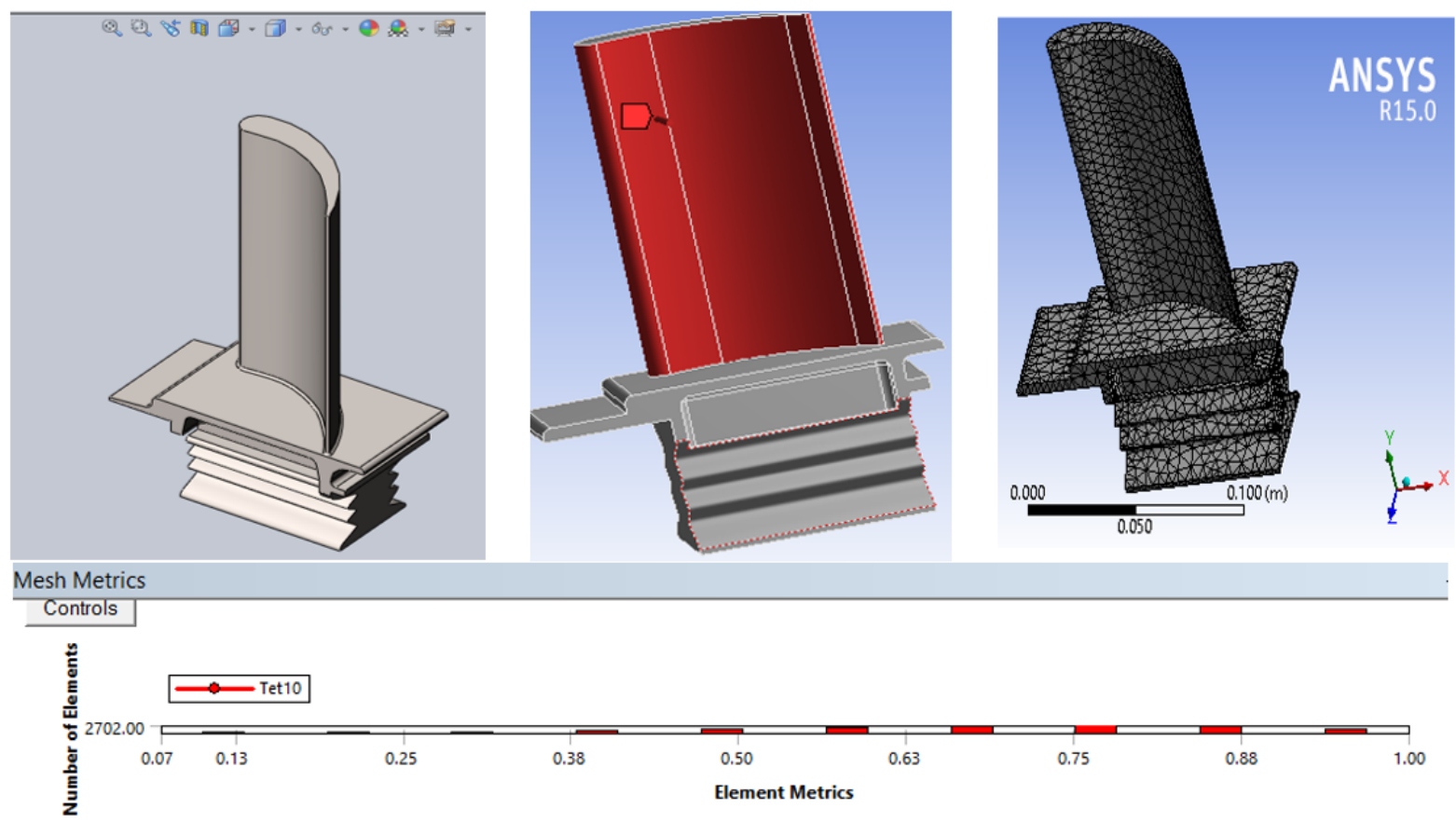

Fig. 3. Gas Turbine Blade Geometries in SOLIDWORKS and Meshed Blade using ANSYS

\subsection{Thermal Analysis}

Heat transfer in fluids occurs by means of conduction as well as convection. Force convection is the dominant phenomena in turbine flows. The boundary conditions for steady state thermal analysis as applied to the turbine blade in the analysis are indicated in Table 4. Operational Parameters of the Gas Turbine Blade are presented in Table 5.

Table 4. Steady-state Boundary Condition for the Thermal Analysis

\begin{tabular}{ll}
\hline Parameters & Value \\
\hline Turbine Inlet Temperature $\left({ }^{0} \mathrm{C}\right)$ & 950 \\
Convective Heat Transfer Coefficient On Tip $\left(\mathrm{W} / \mathrm{M}^{2} \mathrm{~K}\right)$ & 800 \\
Convective Heat Transfer Coefficient On Pressure Side $\left(\mathrm{W} / \mathrm{M}^{2} \mathrm{~K}\right)$ & 1000 \\
Convective Heat Transfer Coefficient On Suction Side $\left(\mathrm{W} / \mathrm{M}^{2} \mathrm{~K}\right)$ & 1300 \\
Turbine Exit Temperature $\left({ }^{0} \mathrm{C}\right)$ & 480 \\
\hline
\end{tabular}

Table 5. Operational Parameters of the Gas Turbine Blade

\begin{tabular}{lc}
\hline Pressure (bar) & 8 \\
\hline Speed (rpm) & 5100 \\
Tangential force (N) & 177.48 \\
Axial force (N) & 0.3439 \\
Centrifugal (N) & 40,680 \\
\hline
\end{tabular}




\section{Results and Discussion}

Results obtained from the thermal-structural analysis in this study are presented in this section.

\subsection{Steady-state Thermal Analysis}

In a gas turbine blade, boundary layer develops on the blade surface and the free stream temperature are of interest. This layer acts as a buffer between the solid blade and the hot free stream, and offers resistance to heat transfer. Heat transfer occurs in this viscous layer between the blade and the fluid through both conduction and convection. After inputting the boundary conditions presented in Table 4 and applying it on the gas turbine blade, the following results were obtained for IN 738 and U500 blade materials as shown in Figs. 4-7. This boundary condition caused convective heat transfer to occur through one or more flat or curved faces (in contact with a fluid). Exhaust gases from the combustor are directed through the turbine in such a manner that the hottest gases impinge on turbine blades. It was observed that the maximum temperature is experienced at the leading edge of the blade, however, there was a temperature fall from the leading edge to the trailing edge of the blade. Since heat is transferred from the region of high temperature to a region of low temperature, the maximum heat flux was observed at the trailing edge.

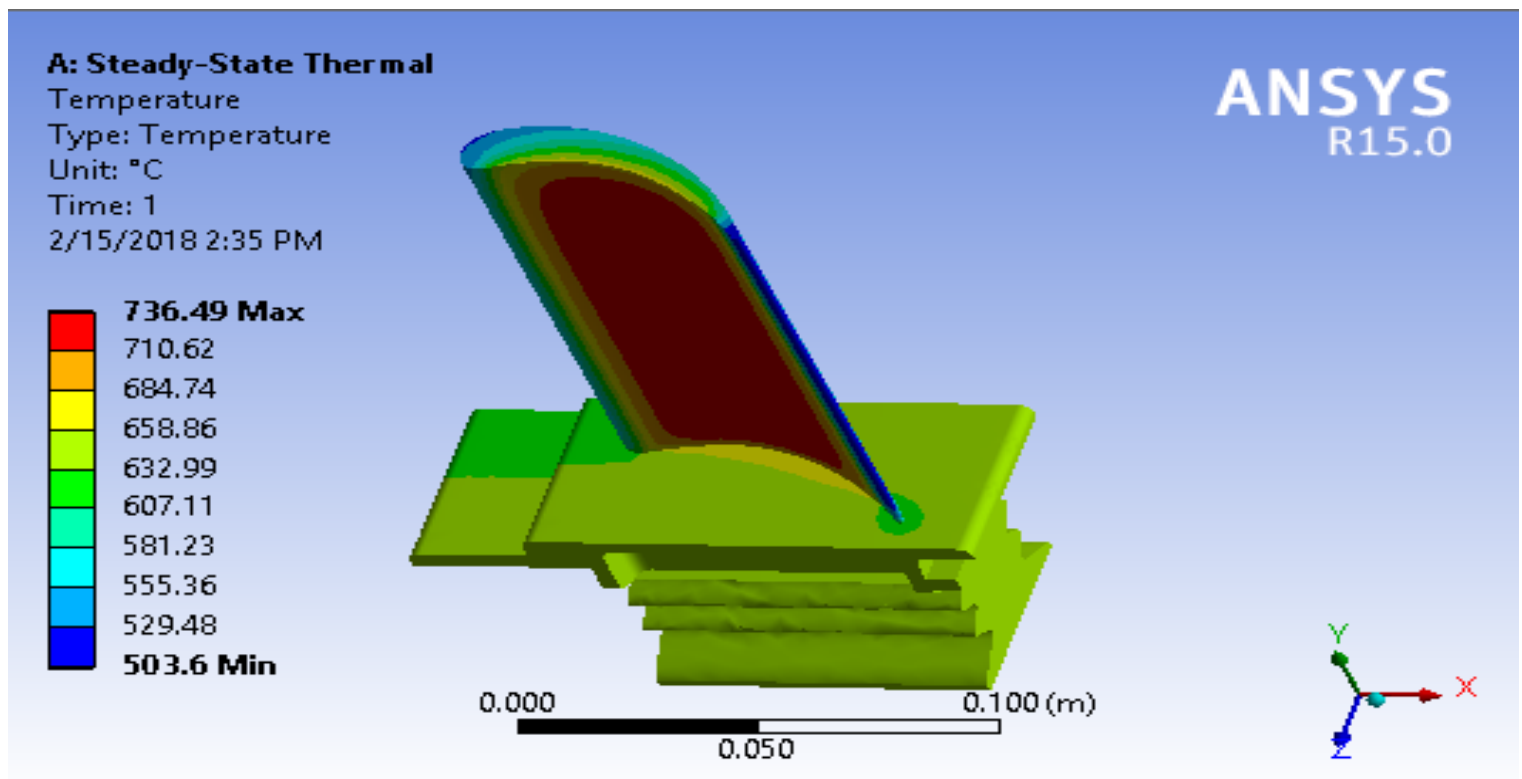

Fig. 4. Temperature distribution on IN738 Turbine Blade Material 


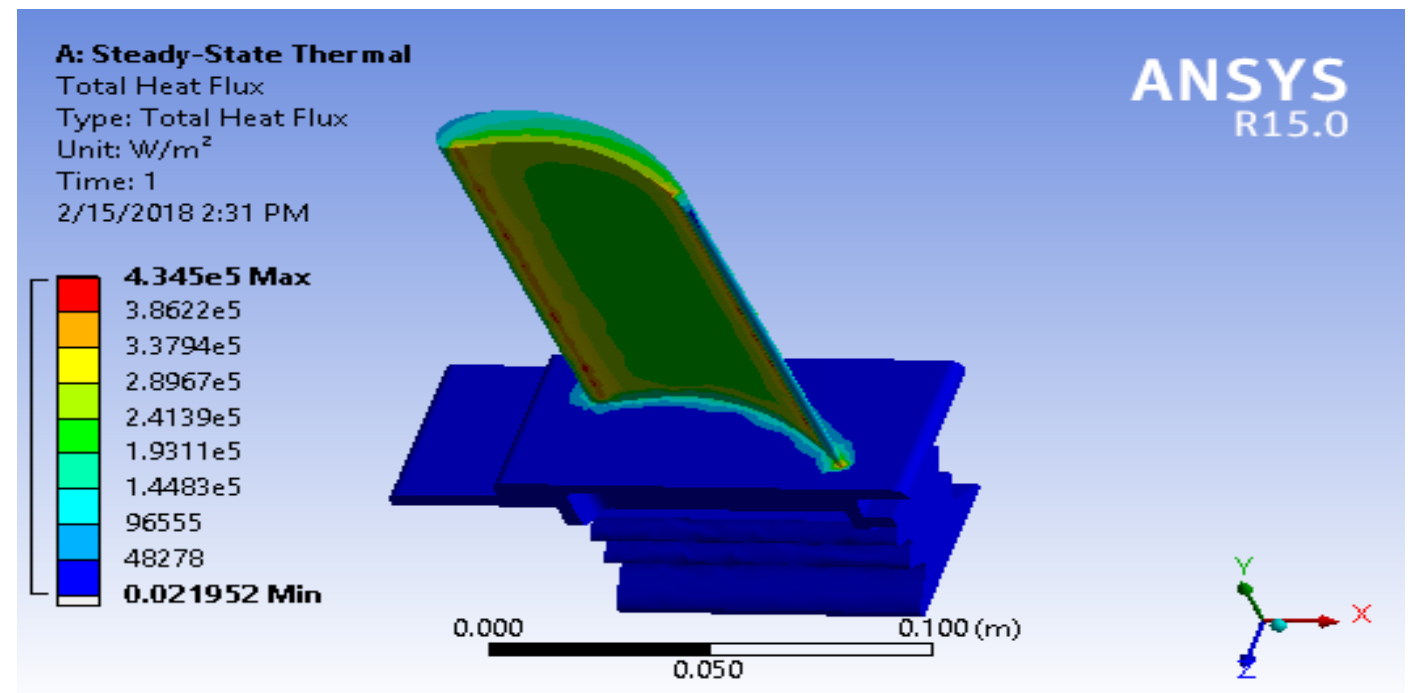

Fig. 5. Heat Flux on IN 738 Turbine Blade Material

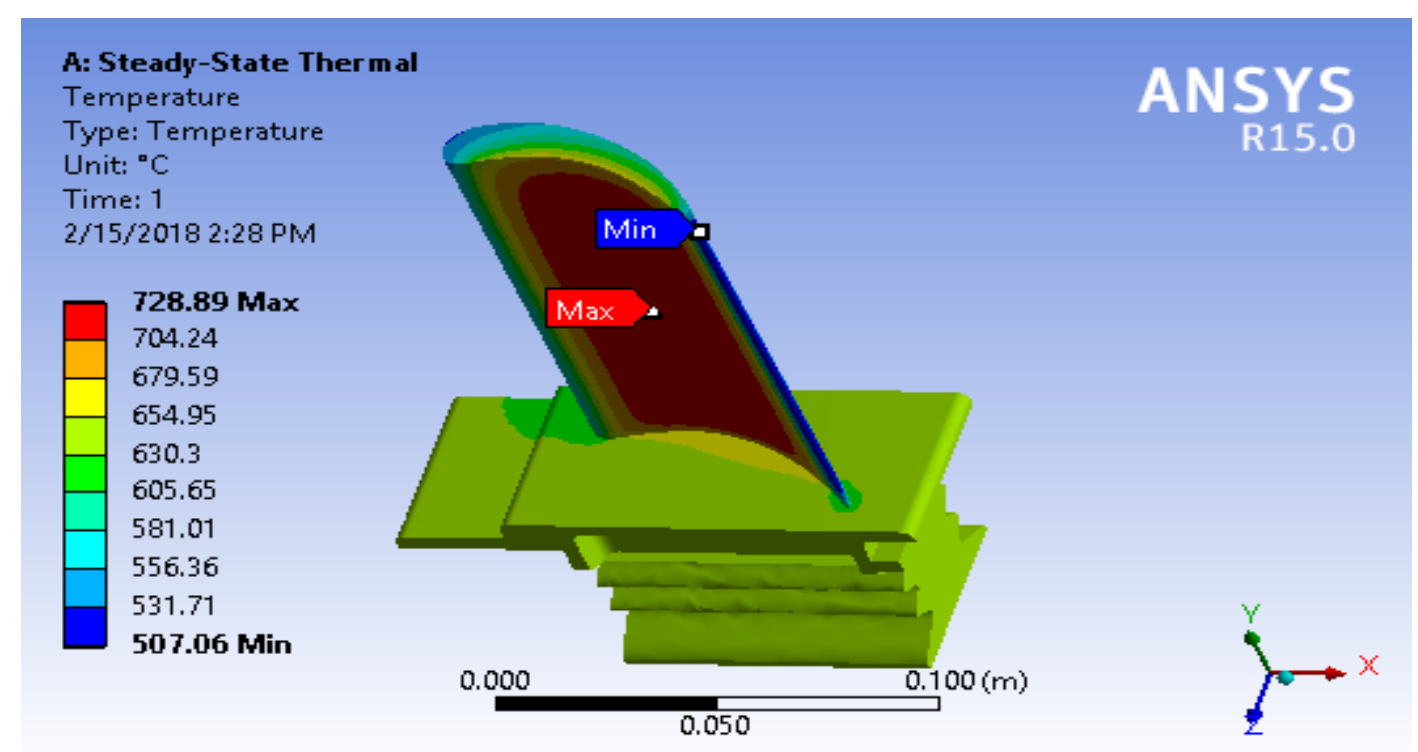

Fig. 6. Temperature distribution on U500 Turbine Blade Material

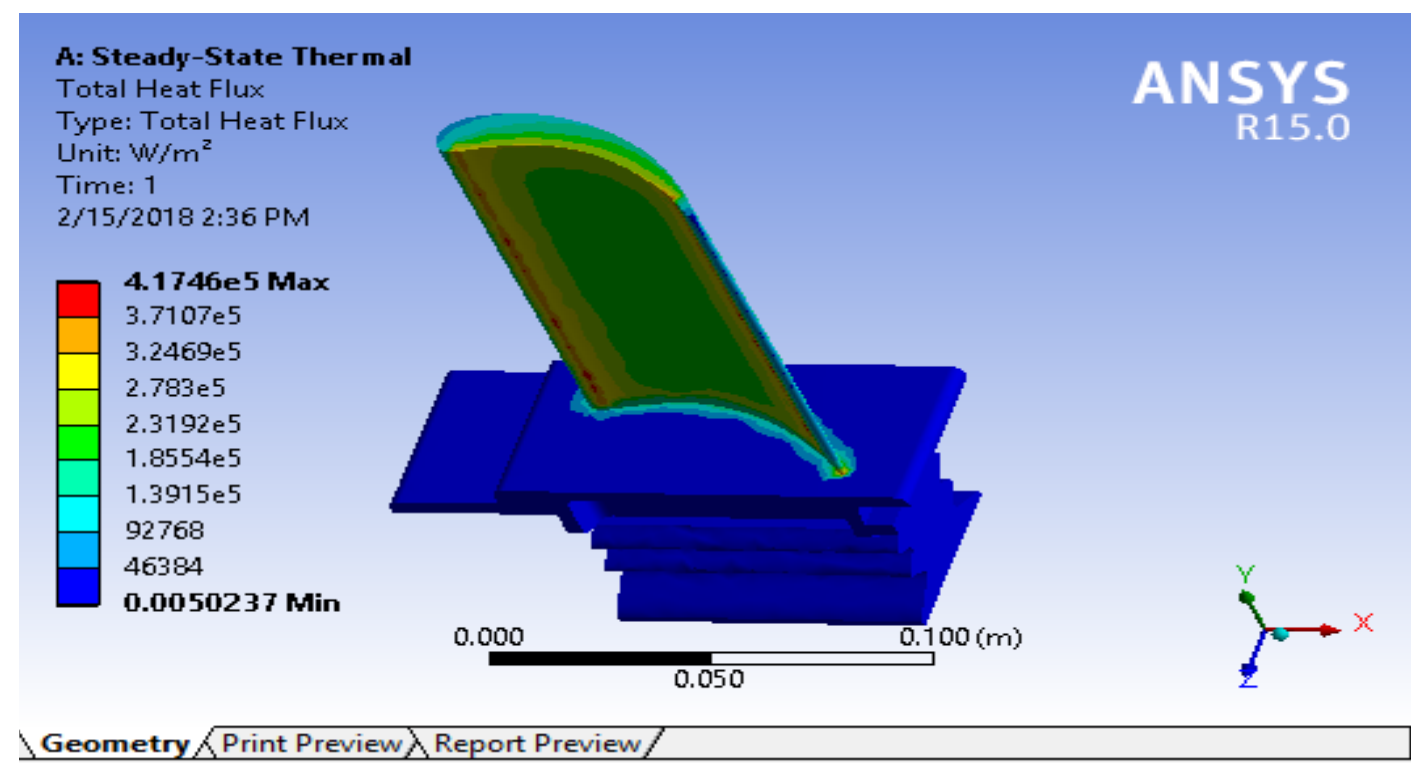

Fig. 7. Heat Flux on U500 Turbine Blade Material 
From Fig. 8, it can be observed that the maximum temperature of the various blade material fall below their corresponding melting temperature. The maximum temperature and heat flux were closely varying between the two turbine blade materials. IN 738 a higher temperature and heat flux characteristics compared to U500. Variations in maximum temperature and heat flux between the two blade materials is due to their differences in material properties.

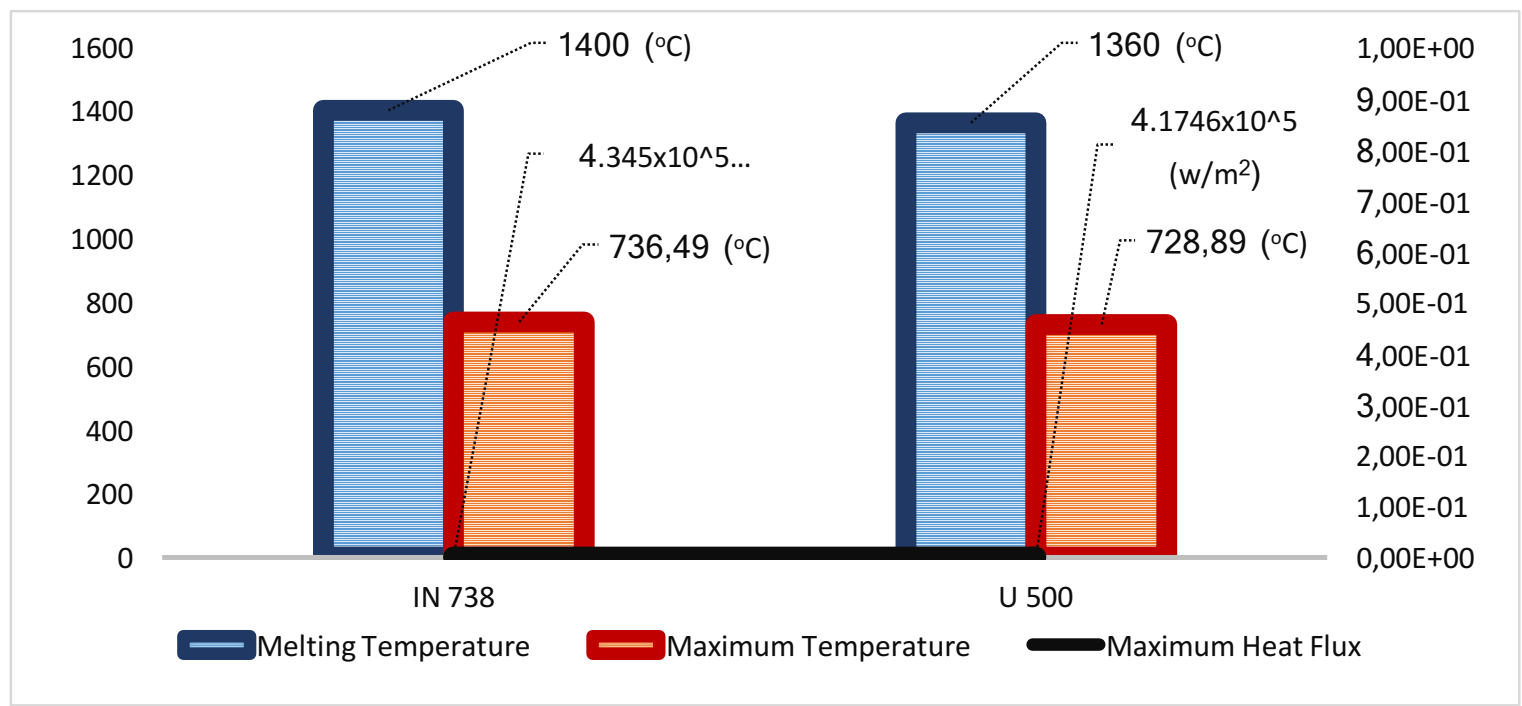

Fig. 8. Maximum Temperature and Heat Flux for Turbine Blade Materials

The temperatures observed were below the melting temperature of the blade materials, as both IN738 and U500 turbine blade materials exhibited high temperatures of $736^{\circ} \mathrm{C}$ and $728^{\circ} \mathrm{C}$ as shown in Fig 8. Depending on the severity of heat flux in the gas turbine engine, the temperature can have significant effects on the overall turbine blade performance. The non-uniform temperature distribution from the tip to the root of the blade materials may induce thermal stresses on the turbine blade, while thermal stresses along with the mechanical stresses set up in the turbine blade during service condition may reduce the life of blade material. Figs. 9-11 represent the results obtained when static structural analysis was performed on IN 738 turbine blade material while Figs. 12-14 represent the results obtained when static structural analysis was performed on U500 turbine blade material.

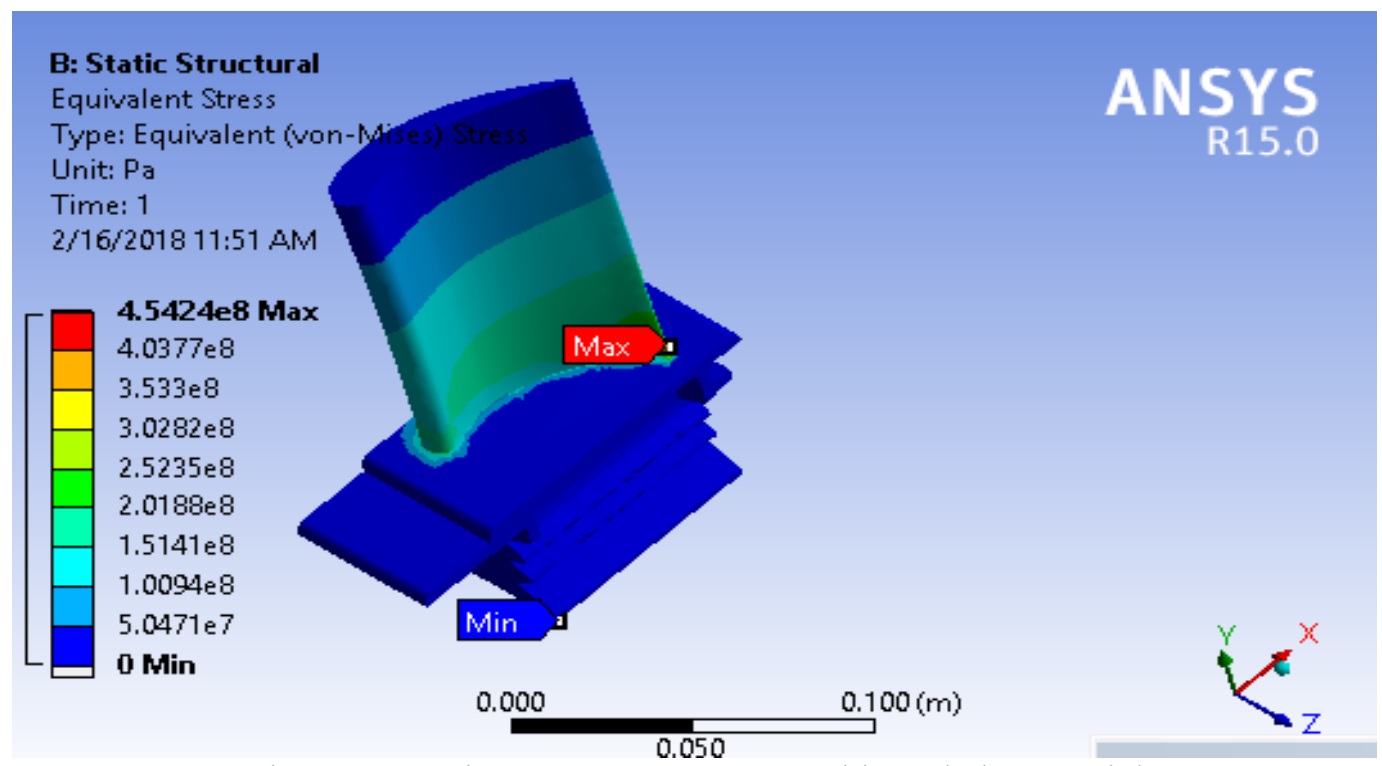

Fig. 9. Von-mises Stress on IN738 Turbine Blade Material 


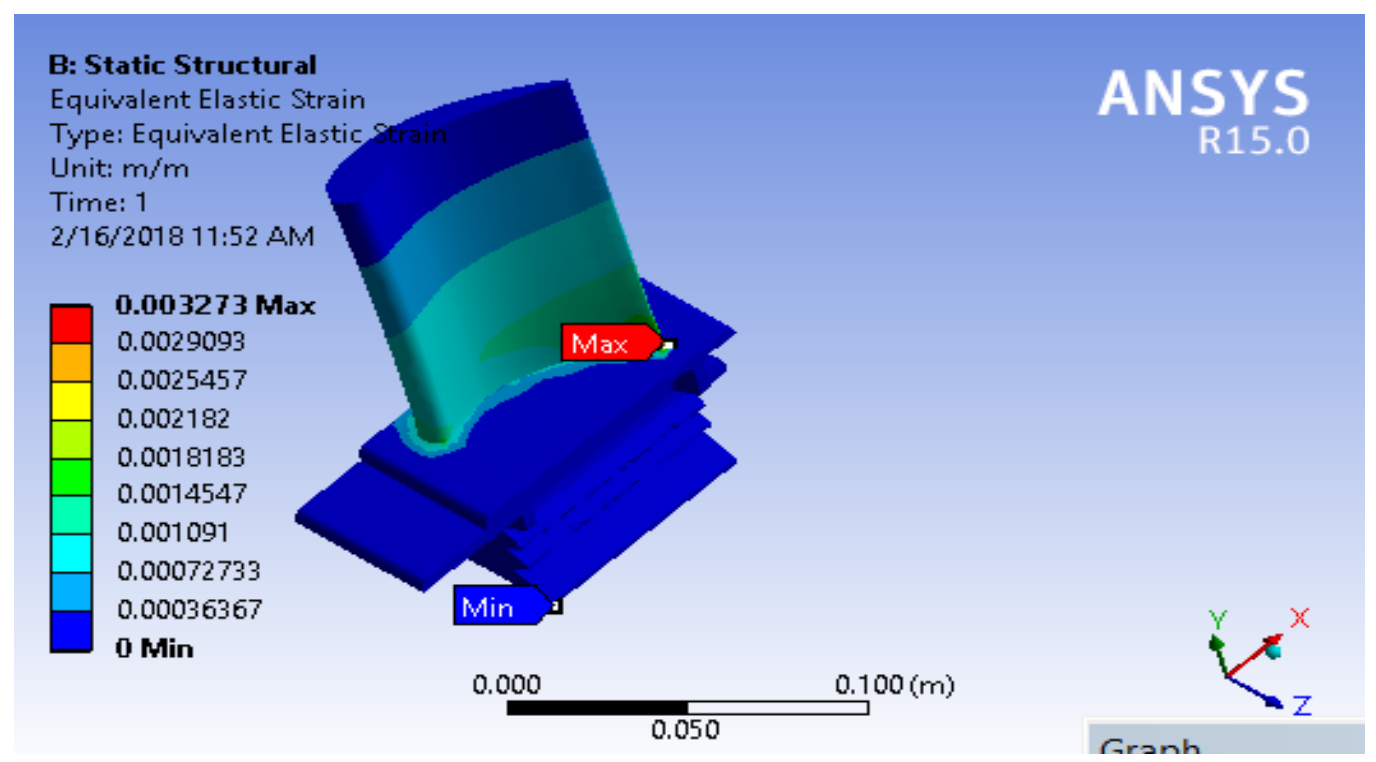

Fig. 10. Elastic Strain on IN738 Turbine Blade Material

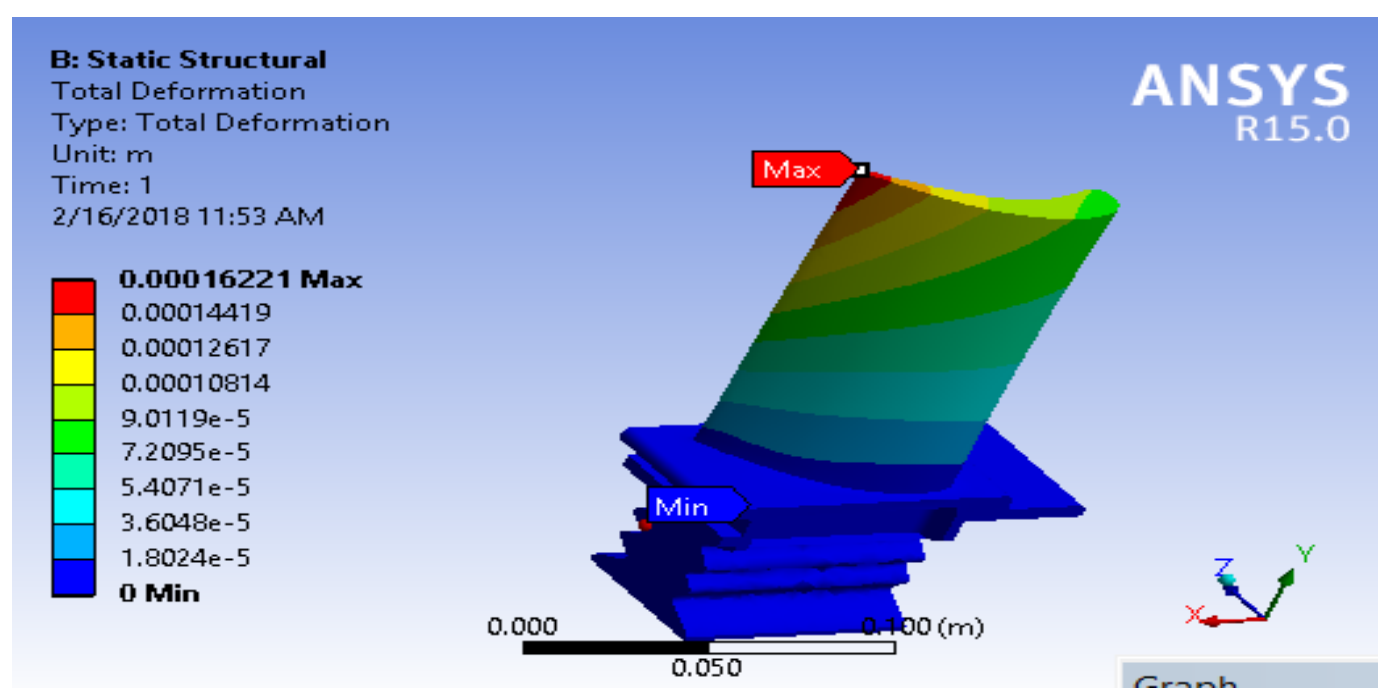

Fig. 11. Total Deformation on IN738 Turbine Blade Material

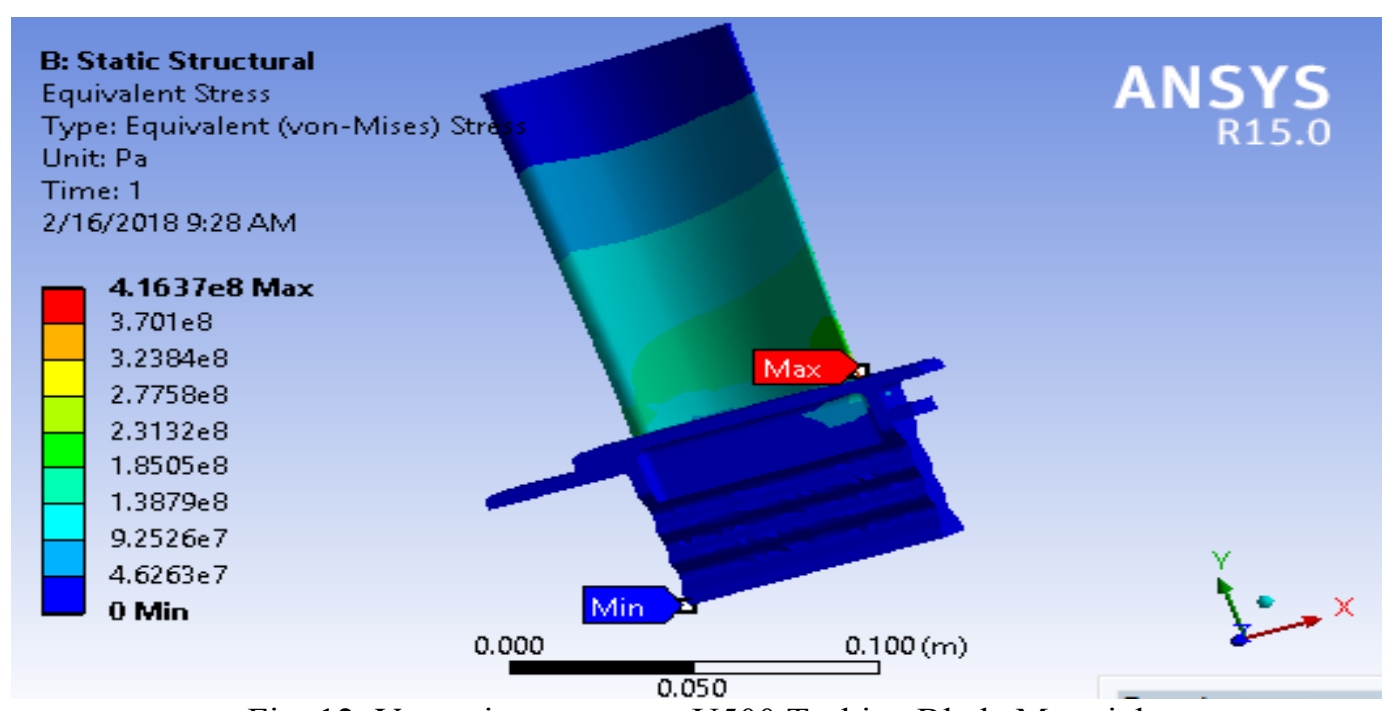

Fig. 12. Von-mises stress on U500 Turbine Blade Material 


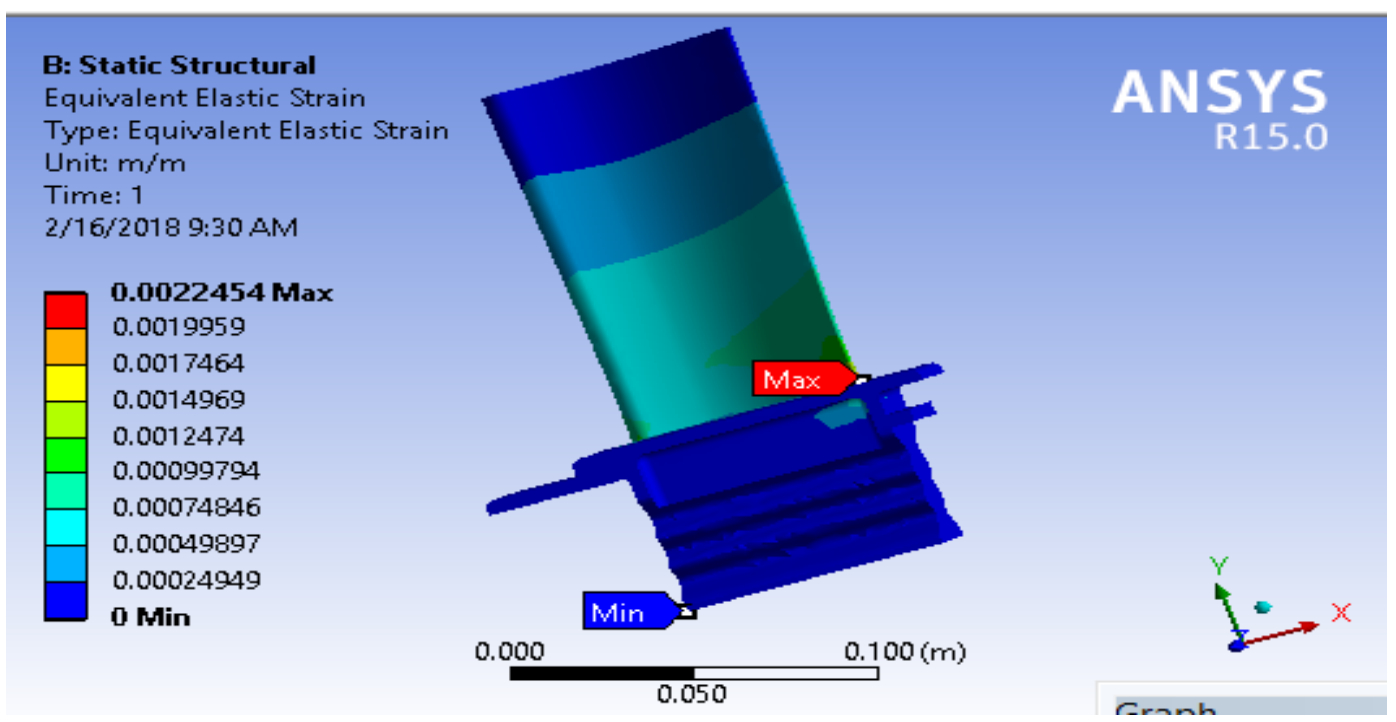

Fig. 13. Elastic Strain on U500 Turbine Blade Materia

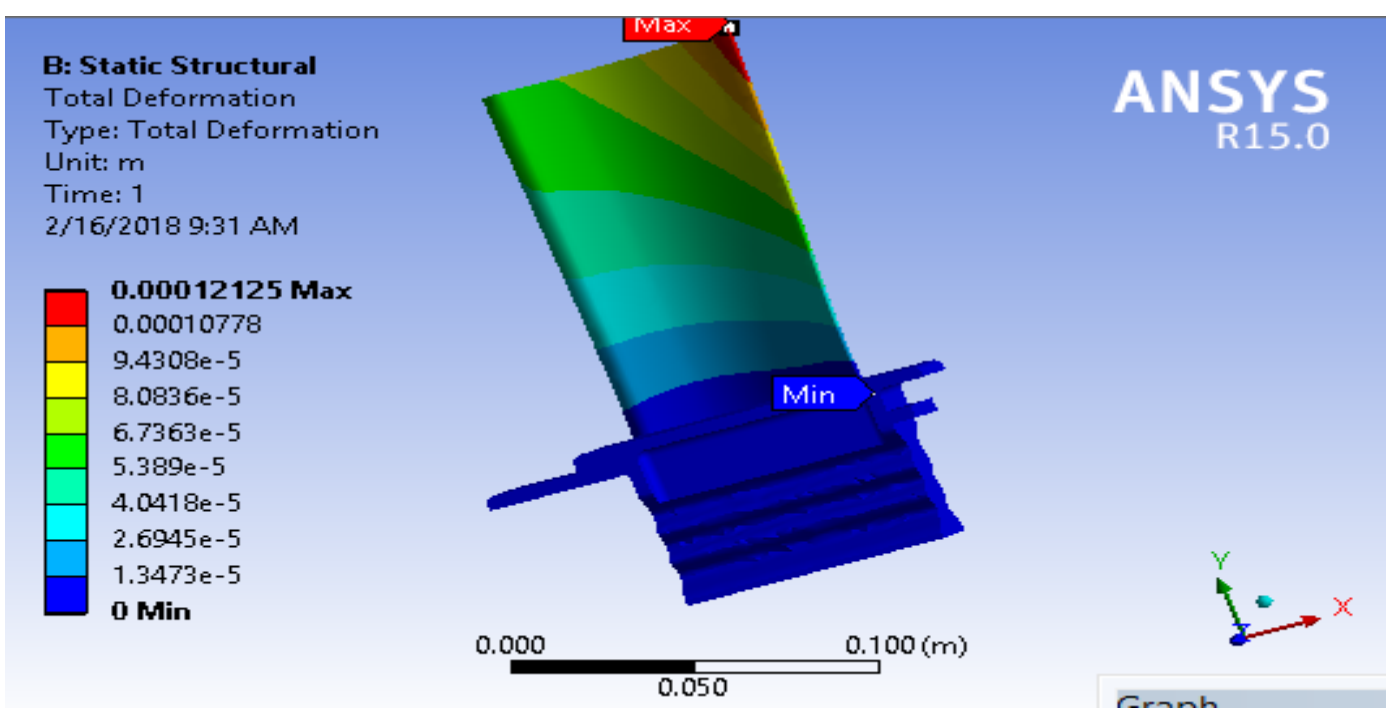

Fig. 14. Total Deformation on U500 Turbine Blade Material

A summary of results obtained from the static structural analysis for both IN738 and U500 turbine blade materials is presented in the in Fig. 15. The results presented in Fig. 15 were extracted from the results of stress, strain and deformation from the structural analysis in Figs. 12-14 respectively. The maximum stress exhibited by IN738 blade material and U500 is below their corresponding yield strength. For failure not to occur, the stresses exhibited by the blade materials must be below their yield strength. Therefore, IN738 and U500 are safe under the specified boundary conditions in this study. 


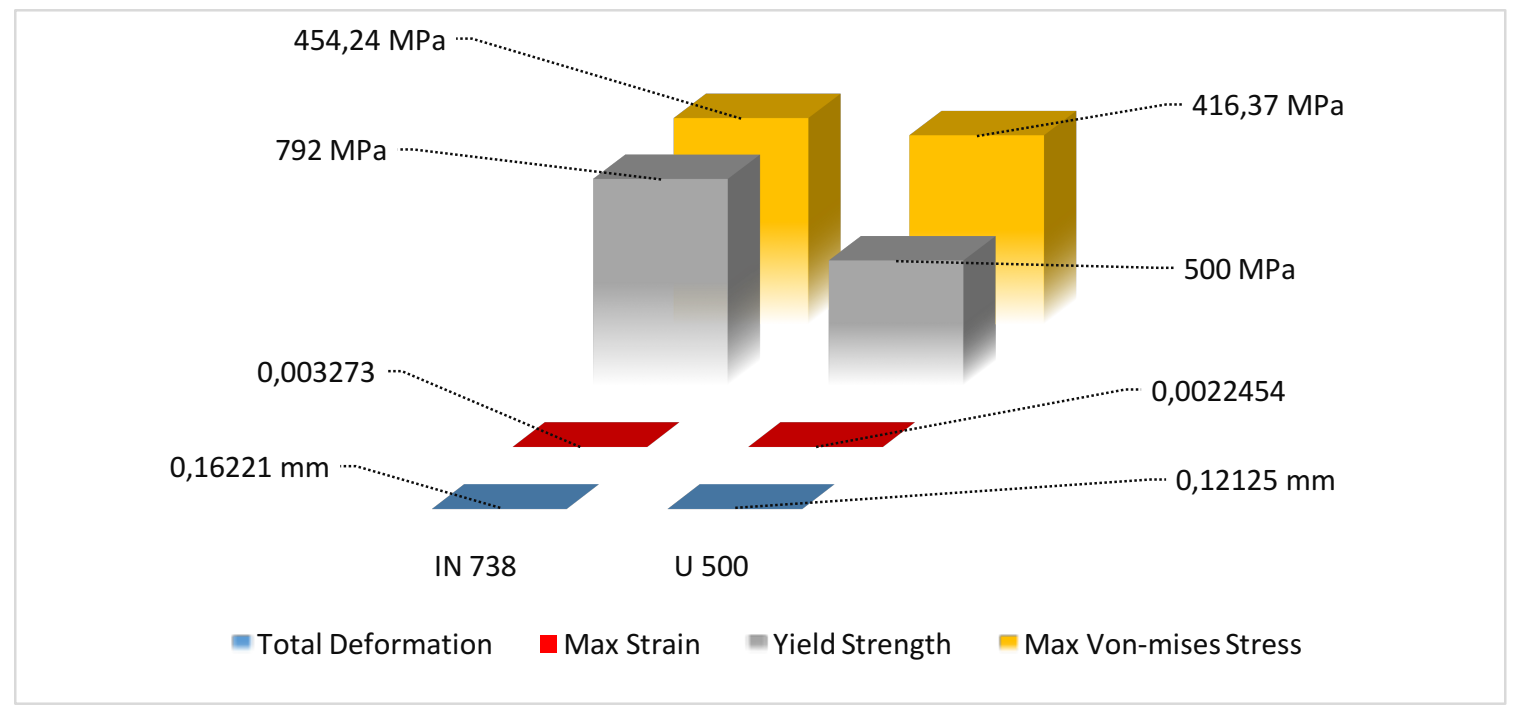

Fig. 15. Variations of Structural Parameters across Different Materials

Static-Structural analysis was performed on the turbine blade to analyze the stress, strain and deformation on the turbine blade. A pre-stress from the steady state thermal analysis in addition to the structural load was performed on the blade to determine the failure criteria on the blade material. The yield criteria was used to relate multi-axial stress state with the uniaxial stress state. Von-mises (Equivalent stress) is part of the maximum equivalent stress failure theory used to predict yielding in a ductile material. The actual structure usually exhibits multi-axial stress state. The yield criterion provides a scalar invariant measure of the stress state of the material which is compared with the uniaxial stress state. Generally, a stress state possesses two components namely;

i. Hydrostatic stress: which generates change in volume.

ii. Deviatoric stress: which generates angular distortion (change in shape).

The von Mises yield criterion states that yielding will occur whenever the distortion energy in a unit volume equals the distortion energy in the same volume when uni-axially stressed to the yield strength. Therefore, if von Mises equivalent stress exceeds the uniaxial material yield strength, yielding will occur. The blade root has more strength when compared to the blade span (free end of the blade). After incorporating the boundary conditions and various forces acting on the blade from Table 4 and 5, color profile on the turbine blade model indicated areas of maximum and minimum stress, strain and deformation. The red contours represents maximum values while the blue contours represents minimum values. It was found that maximum stress and strain developed at the joint sections of root and blade volumes (trailing edge), while maximum deformation is found at the blade tip. Variation of deformation, stress, and strain for the two materials were examined from the structural analysis. Maximum deformation was observed at the top blade tip sections and minimum elongations at the root of the blade as shown in Figs. 11 and 14. To avoid failure of the gas turbine blade due to creep, deformation on the blade must be as less as possible. Comparing the maximum deformation under the same load condition for both materials, total deformation for IN738 was $0.16221 \mathrm{~mm}$ whereas, the total deformation obtained for U500 blade material was $0.12125 \mathrm{~mm}$ as illustrated in Fig. 15. Deformation values obtained by Bhupendra et al. [15] from super alloy (N-155 nickel based alloy) in the category of IN738 and U500 ranged between $0.000177 \mathrm{~mm}$ and $0.000274 \mathrm{~mm}$ which are less compared to deformation values obtained in this study. This may have been due to the variations in material properties and compositions. Maximum stresses and strains were observed on the trailing edge, at the joint between the blade span and the root. The maximum 
von-mises stress for U500 (yield strength of $500 \mathrm{MPa}$ ) and IN738 (yield strength of 7920) was below the corresponding yield strength of the materials. Comparing the maximum von-mises stresses for both materials under same loading condition, the von-mises stress on IN738 was $454 \mathrm{MPa}$ while von-mises stress of $416 \mathrm{MPa}$ was obtained for U500 blade material as shown in Figs. 9 and 12. Also, comparing the results obtained for maximum strain across the various materials, strain on IN738 was 0.003273 while the strain value obtained for U500 was 0.0022454 as shown in Figs. 10 and 13 respectively. The gas turbine blade is prone to failure when the maximum stress at the trailing edge near the root of the blade exceeds the yield stress of the blade material. From the result obtained from the thermal analysis, variations in the temperature of the two material indicated that maximum temperatures prevailed at the leading edge of the blade, while temperatures distribution below the maximum temperature was observed at the trailing edge and along the blade root. Hence, both turbine blade materials investigated in this study are safe as potential gas turbine blade materials, as their maximum service temperatures were below their melting temperature, also, as their yield strengths obtained in the course of the analysis were below their yield strength.

\section{Conclusion}

Turbine Blades are one of the most important components in the gas turbine engine. The blades are operated in harsh environmental condition at elevated temperature, high pressure and large centrifugal forces that hampers the performance and longevity of the blade material in service condition. The turbine blade material is exposed to unforeseen failure depending on the severity, and this necessitated the thermal and structural static analysis carried out in this study. From the analysis of the results, it was observed that the temperature on the turbine blades for both materials was below the melting temperature of the blade materials. Maximum temperatures were observed at the leading edge of the blade and decreased towards the trailing edge and blade root. Maximum von-mises stresses and strains were observed near the root of the turbine blade and upper surface along the blade roots. Total deformation obtained from each blade analysis were negligible, as $0.16221 \mathrm{~mm}$ was obtained for IN 738 and $0.12125 \mathrm{~mm}$ obtained for U 500. This report serves as a guideline for the selection of suitable materials for minimal gas turbine blade failure and optimal working scenario.

\section{References}

[1] Sulaiman, K.S., Rameshkumar, G.R., Vibration Diagnosis Approach for Industrial Gas Turbine and Failure Analysis, British Journal of Applied Science \& Technology, 14(2), 19, 2016.

[2] Kalapala P., Prasad, B.A., Anandarao, M., Material Optimization and Dynamic Approach for performance criteria in application to Gas Turbine Blade to overcome resonance; International Journal of Scientific \& Engineering Research, 8(6), 189-196, 2017.

[3] Hassan M., Vibratory Analysis of Turbomachinery Blades, Rensselaer Polytechnic Institute, Hartford, Connecticut, 2008.

[4] Gharzwan M.A., High Cycle Fatigue Testing of Steel for Federal Aviation Administration (FAA), Department of Mechanical Engineering, California State University, Sacramento, (2017).

[5] Mohamad, B.A., Abdelhussien, A., Failure Analysis of Gas Turbine Blade Using Finite Element Analysis, International Journal of Mechanical Engineering and Technology (IJMET) 7(3), 299-305, 2016. 
[6] Boyce, M.P., The Gas Turbine Handbook, Gulf Professional Publishing, Houston Texas, $2^{\text {nd }}$ edition 2002.

[7] Ikpe A.E., Owunna I., Ebunilo, P.O., Ikpe, E., Material Selection for High Pressure (HP) Turbine Blade of Conventional Turbojet Engines, American Journal of Mechanical and Industrial Engineering 1(1), 1-9, 2016.

[8] Nathan, S., Jewel in the Crown: Rolls-Royce's Single-Crystal Turbine Blade Casting Foundry, [online] available at, https://www.theengineer.co.uk/issues/june-2015online/jewel-in-the-crown-rolls-royces-single-crystal-turbineblade-casting-foundry/, 2015.

[9] Choi Y, Lee K, Investigation of blade failure in a gas turbine, Journal of Mechanical Science and Technology, 24(10), 1969-1974, 2010.

[10] Umamaheswararao, L., Mallikarjunarao, K., Design and analysis of a gas turbine blade by using FEM, International Journal of Latest Trends in Engineering and Technology (IJLTET), 4(4), 19-24, 2014.

[11] Kumar. R.R. Pandey, K.M., Static Structural and Modal Analysis of Gas Turbine Blade, IOP Conference Series, Materials Science and Engineering 225(012102), 1-9, 2017.

[12] Sushila, R., Atul, K.A. Vikas, R., Failure Analysis of a First Stage IN738 Gas Turbine Blade Tip Cracking in a Thermal Power Plant, Case Studies in Engineering Failure Analysis, 8, 1-10, 2017.

[13] Rao, V.N., Kumar, I.N., Madhulata, N., Abhijeet, A., Mechanical Analysis of $1^{\text {st }}$ Stage Marine Gas Turbine Blade, International Journal of Advanced Science and Technology, 68, 57-64, 2014.

[14] Nageswara, R.M., Materials for Gas turbines, Advances in Gas Turbine Technology, 293314, Intech Publisher, ISBN: 978-953-307-611-9, 2011.

[15] Bhupendra, E.G., Sachin, V.B., Kapil B.S., Vibration Analysis of Gas Turbine Blade Profile Using FEM Technique and Tool, International Journal of Research in Advent Technology, 2(1), 182-189, 2014. 